\title{
Multiple Sclerosis Pathology
}

\author{
Hans Lassmann \\ Center for Brain Research, Medical University of Vienna, A-1090 Wien, Austria \\ Correspondence: hans.lassmann@meduniwien.ac.at
}

Multiple sclerosis (MS) is a chronic inflammatory demyelinating disease of the central nervous system (CNS), which gives rise to focal lesions in the gray and white matter and to diffuse neurodegeneration in the entire brain. In this review, the spectrum of MS lesions and their relation to the inflammatory process is described. Pathology suggests that inflammation drives tissue injury at all stages of the disease. Focal inflammatory infiltrates in the meninges and the perivascular spaces appear to produce soluble factors, which induce demyelination or neurodegeneration either directly or indirectly through microglia activation. The nature of these soluble factors, which are responsible for demyelinating activity in sera and cerebrospinal fluid of the patients, is currently undefined. Demyelination and neurodegeneration is finally accomplished by oxidative injury and mitochondrial damage leading to a state of "virtual hypoxia."

M ultiple sclerosis (MS) has historically been defined as a chronic inflammatory disease of the central nervous system (CNS), which leads to large focal lesions in the white matter of the brain and spinal cord, characterized by primary demyelination with a variable extent of axonal loss (Charcot 1880). Demyelination and neurodegeneration in the MS brain is associated with a profound astroglia reaction, forming a dense glial scar in long-standing established lesions. For some time, the view on MS pathology centered on focal demyelinated plaques in the white matter. Later it became clear that lesions are also present in the gray matter, including the cortex, the basal ganglia, brain stem, and the gray matter of the spinal cord (Brownell and Hughes 1962). Furthermore, there is neurodegeneration, which affects the brain and spinal cord in a global sense, giving rise to axonal loss in the normal- appearing white matter, and diffuse neurodegeneration in the entire gray matter. These changes finally result in profound brain tissue loss and atrophy, which is most pronounced in the progressive stage of the disease (Mahad et al. 2015). The general pathology of MS has been described in detail in several recent reviews (Lassmann et al. 2007; Kutzelnigg and Lassmann 2014) and, therefore, this article focuses on some essential features. In addition, new findings related to inflammation and its relation to demyelination and neurodegeneration will be discussed in more detail.

\section{BASIC PATHOLOGY OF MULTIPLE SCLEROSIS}

The diagnostic hallmark of MS is the presence of large confluent demyelinated lesions in the

Editors: Howard L. Weiner and Vijay K. Kuchroo

Additional Perspectives on Multiple Sclerosis available at www.perspectivesinmedicine.org

Copyright (C) 2018 Cold Spring Harbor Laboratory Press; all rights reserved; doi: 10.1101/cshperspect.a028936

Cite this article as Cold Spring Harb Perspect Med 2018;8:a028936 
H. Lassmann

white and gray matter of the CNS (Fig. 1) (Charcot 1880). The most important feature is the selective and primary nature of demyelination with the destruction and loss of oligodendrocytes (Babinski 1885; Prineas 1985). Although myelin is completely lost, axons are preserved to a large extent, and the amount of axonal destruction is variable between different patients and even between lesions in the same patient (Ferguson et al. 1997; Trapp et al. 1998; for a historical review, see Kornek and Lassmann 1999). Lesions occur on the background of in-
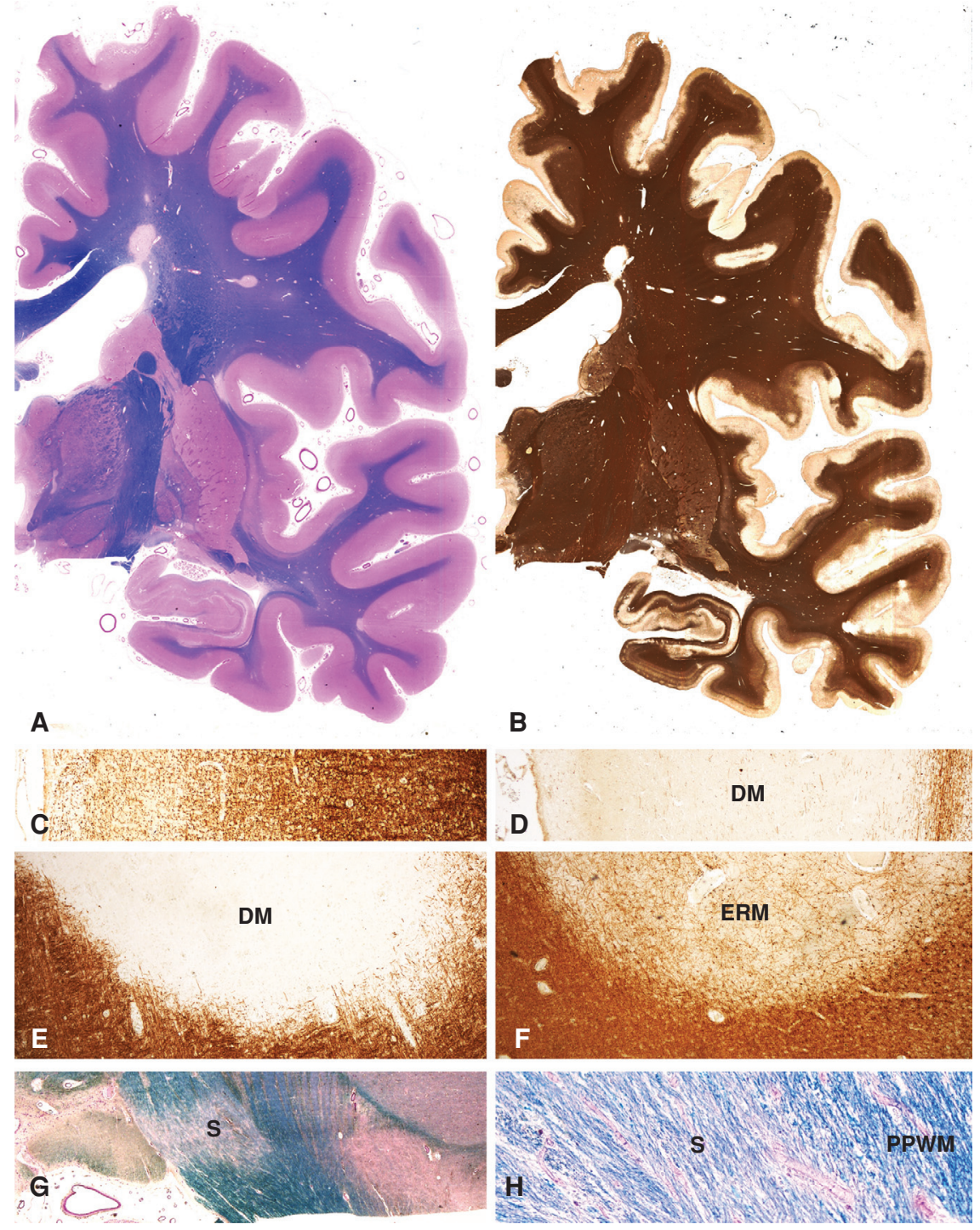

Figure 1. Pathological changes in the brain of a patient with secondary progressive multiple sclerosis (MS). Large confluent focal demyelinated lesions are present in the white matter $(A)$. In addition, there is extensive subpial cortical demyelination, which can only be seen when sensitive immunocytochemistry for myelin proteins (e.g., proteolipid protein) is used $(B)$. In contrast to the normal pattern of myelin in the cerebral cortex, as shown in $C$, there is complete loss of myelin in subpial lesions $(D)$. Demyelinated plaques in the white matter may appear as inactive demyelinated lesions ([DMs] in $E$ ), as early remyelinated lesions with a low density of thin myelin sheaths only visible by immunocytochemistry for myelin proteins (ERM in $F$ ) or as remyelinated shadow plaques $(G$ and $H$ ). 
flammation, consisting of $\mathrm{T}$ lymphocytes, $\mathrm{B}$ lymphocytes, and plasma cells (Fig. 2). The inflammatory reaction is initiated around postcapillary venoles and veins (Charcot 1880). Thus, in the initial stages of lesions, perivenous demyelination is seen and these lesions fuse to confluent demyelinated plaques, which expand at their border into the surrounding normalappearing white matter. This gives rise to the typical perivenous extensions of established lesions, the so-called Dawson fingers (Dawson 1916). The demyelinating process is associated with activation of astrocytes during the state of active tissue injury and the formation of gliotic scars in inactive lesions. MS lesions can in part become remyelinated as a result of recruitment and differentiation of oligodendrocyte progenitor cells (Prineas et al. 1993).

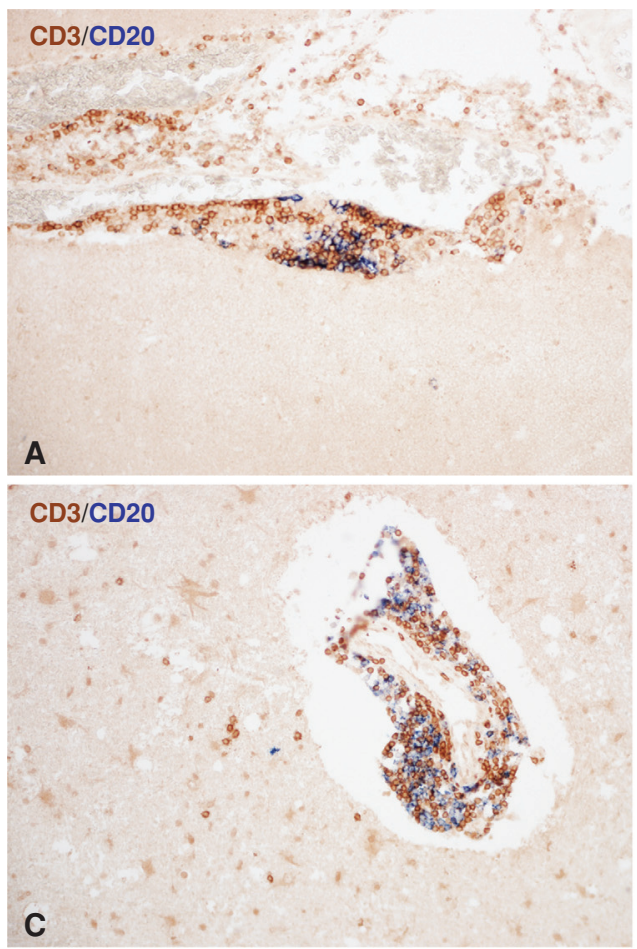

Similar perivenous and confluent demyelinated lesions are also formed in the gray matter (Fig. 1), including the cerebral (Kidd et al. 1999) and cerebellar cortex (Kutzelnigg et al. 2007), the deep brain stem nuclei (Cifelli et al. 2002; Vercellino et al. 2009; Haider et al. 2014), and the gray matter of the spinal cord (Fog 1950). In addition, in the cerebral cortex, widespread subpial cortical demyelination is present, in particular in the progressive stage of the disease, and active subpial demyelination is oriented toward inflammatory infiltrates in the leptomeninges (Bo et al. 2003; Kutzelnigg et al. 2005). Inflammation in and around MS lesions is seen in all stages of the disease, thus being present not only in the brain of patients who died in early (relapsing) MS but also in primary or secondary progressive MS. It is most pronounced within actively de-

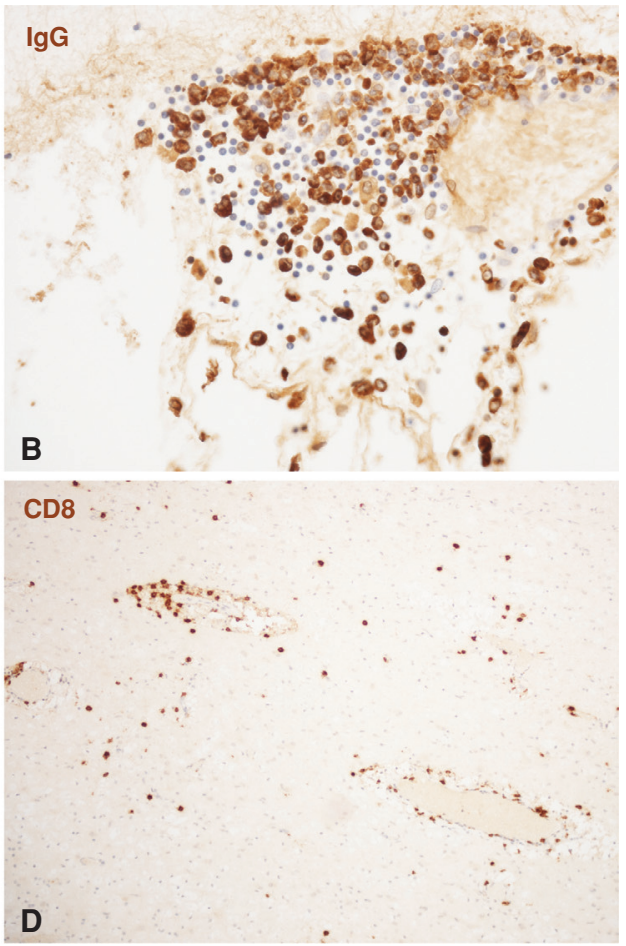

Figure 2. Inflammation in the multiple sclerosis (MS) brain. Meningeal inflammatory infiltrates are composed of $\mathrm{CD}^{+} \mathrm{T}$ cells, $\mathrm{CD} 20^{+} \mathrm{B}$ cells $(A)$, and immunoglobulin-positive plasma cells $(B)$. The inflammatory infiltrates appear as aggregates with separated domains for T cells, $B$ cells, and plasma cells ( $A$ and $B$ ). No lymphocytes are present in the underlying cortical tissue $(A)$. In white matter lesions, profound inflammatory infiltrates are seen in the perivascular space, which contain T cells and $\mathrm{B}$ cells $(C)$. In addition, there is a diffuse infiltration of $\mathrm{T}$ cells, but not of B cells in the lesioned tissue $(C)$. The diffuse infiltrates in the lesions nearly exclusively consist of CD ${ }^{+}$ T lymphocytes $(D)$. 
myelinating lesions, but is also seen in inactive or remyelinated plaques as well as in the normalappearing white matter (Frischer et al. 2009).

The selective perivenous and confluent primary demyelination with oligodendrocyte loss distinguishes MS from other diseases with focal white and gray matter lesions. As examples, in neuromyelitis optica, focal demyelinated lesions with severe axonal destruction follow a primary astrocyte damage triggered by specific antibodies against aquaporin 4 (Misu et al. 2013). In other inflammatory conditions, primary demyelination may follow virus infection of oligodendrocytes (e.g., progressive multifocal leukoencephalopathy). In this situation, demyelination initially affects the territories of single oligodendrocytes, but does not reflect the MS typical perivenous pattern (Bauer et al. 2015). Focal white matter lesions in other inflammatory diseases or stroke are mainly destructive with parallel loss of myelin, oligodendrocytes, and axons.

\section{Active Lesions}

Active demyelination or tissue injury is associated with densely populated phagocytic cells, which reveal a morphological phenotype of activated microglia or macrophages (Fig. 3) (Prineas 1985). Microglia activation is most pronounced at the edge of actively demyelinating lesions but also abundant in the periplaque or even in the distant normal-appearing white matter. In the periplaque, white matter clusters of activated microglia are frequently encountered, which in part surround degenerating axons (Prineas et al. 2001). In the demyelinated center of active lesions, cells with a microglia phenotype are rare, but the majority of phagocytic cells present as macrophages (Fig. 3A). Whether the macrophages in the plaque center are derived from the pool of activated microglia or from hematogenous monocytes is unresolved. Macrophages contain remnants of the destroyed myelin sheaths and the immunocytochemical profile of different minor and major myelin proteins within the degradation products allow an exact staging of the activity of the lesion (Brück et al. 1995). Microglia and macrophages in the MS brain present with a phenotype, which is inter- mediate between proinflammatory (M1) or antiinflammatory (M2) cells (Vogel et al.2013). However, at sites of active demyelination and tissue injury, they highly express nicotinamide adenine dinucleotide phosphate (NADPH) oxidase, indicating oxidative tissue damage. NADPH oxidase expression is reduced or lost in later stages of active lesions when macrophages have taken up myelin or tissue debris (Fischer et al. 2012).

Such classical active lesions, described above, are mainly seen in patients who have died in early disease stages, such as acute MS or relapsing remitting MS (Frischer et al. 2015); they can be distinguished from slowly expanding active lesions, which are most frequently seen in patients with progressive MS (Fig. 3C,D) (Prineas et al. 2001). The slowly expanding lesions show an inactive demyelinated center and a rim of activated microglia at the edge with some intermingled cells with a macrophage phenotype, which contain myelin degradation products. In addition, acute axonal injury, reflected by the presence of axons with disturbed fast axonal transport or of axonal end bulbs, is not only seen in classical active lesions but also at the active edge of slowly expanding plaques (Frischer et al. 2015).

\section{Inactive Lesions}

Inactive lesions are most abundant in the MS brain. They are sharply demarcated and show primary demyelination, partial axonal preservation, and reactive gliosis (Fig. 1E). A variable degree of microglia activation is present in the periplaque white matter, whereas the number of microglia is profoundly reduced in the center of the demyelinated plaque. A dense fibrillary scar tissue fills the space between the demyelinated axons. Importantly, there is a low degree of ongoing acute axonal injury, reflected by the disturbance of fast axonal transport also in inactive lesions, indicating the ongoing demise of chronically demyelinated axons (Kornek et al. 2000).

\section{Remyelinated Shadow Plaques}

Like inactive lesions, remyelinated shadow plaques are sharply demarcated from the sur- 

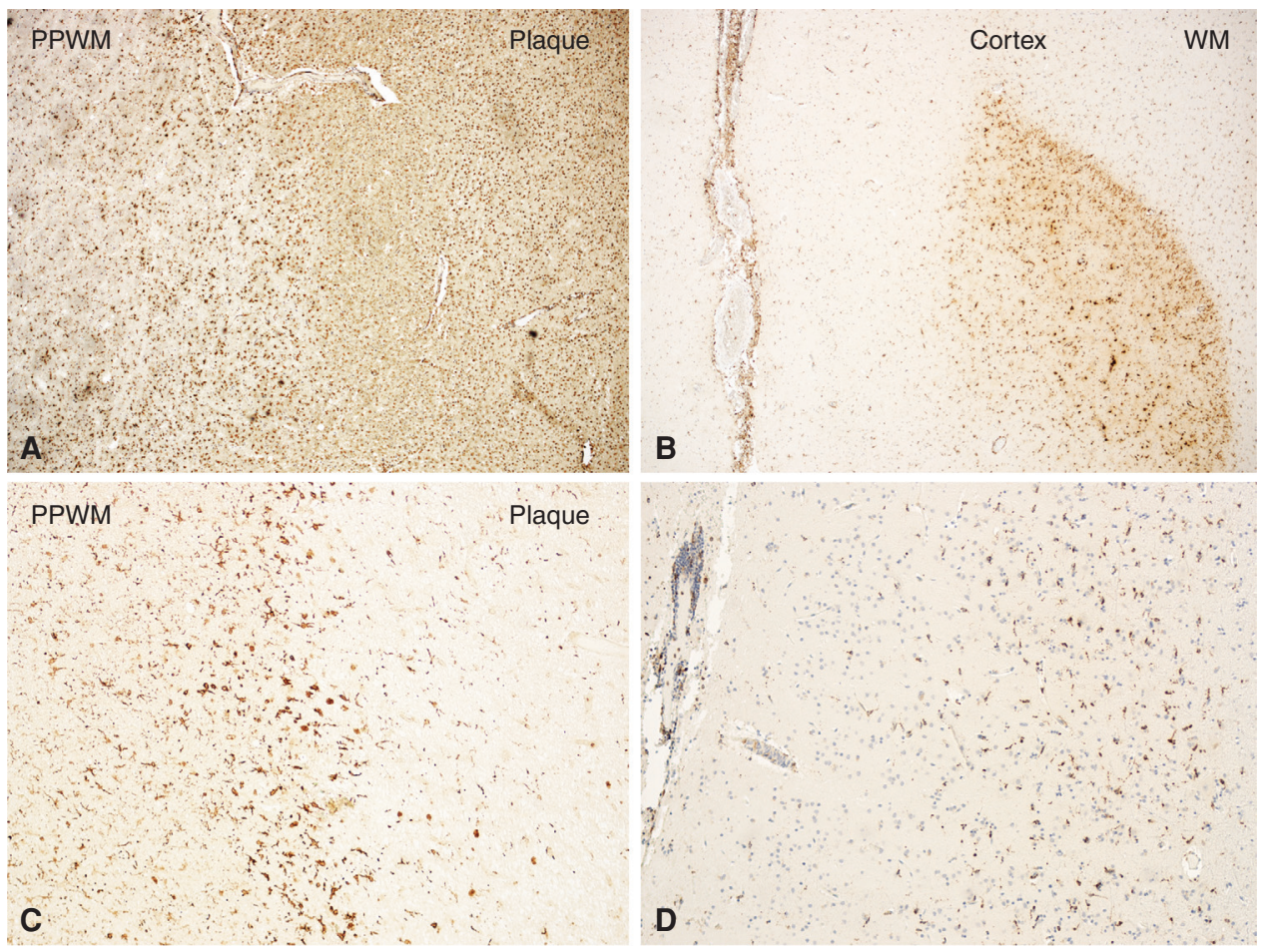

Figure 3. Macrophages and microglia in active multiple sclerosis (MS) lesions. Classical active white matter lesions are densely infiltrated by macrophages and show massive microglia activation with expression of the phagocytosis-associated marker CD68 at the lesion margin and in the adjacent periplaque white matter (PPWM) (A). Active cortical lesions are associated with inflammation in the meninges, whereas the zone of active demyelination is infiltrated by activated microglia with some intermingled macrophages $(B)$. The cortical and white matter areas are labeled as Cortex and WM, respectively. Slowly expanding lesions in the white matter are characterized by a dense rim of activated microglia with some intermingled macrophages at the lesion edge, stained with the microglia marker Iba1. In the lesion center, there is a very low microglia density $(C)$. Similarly, slowly expanding lesions are also seen in the cortex, associated with meningeal inflammation and the presence of activated Iba1-positive microglia at the zone of active myelin injury. As in chronic white matter lesions also in the cortex, the demyelinated zones are nearly completely devoid of microglia $(D)$.

rounding normal-appearing white matter (Fig. $1 \mathrm{~F}-\mathrm{H})$. Axons within these lesions have uniformly thin myelin sheaths with shortened internodes (Prineas et al. 1993). Remyelination may be present in the entire lesion or cover only focal areas within the plaque or the plaque margin. The extent of remyelination varies profoundly between different MS patients and depends in part on lesion location. As an example, remyelinated plaques are more frequent in the subcortical compared to the periventricular white matter (Patrikios et al. 2006). Remyelination is accomplished by new oligodendrocytes derived from the progenitor cell pool, and the extent of remyelination appears to be determined by several factors, such as the presence of progenitor cells, their potential to differentiate into mature myelinating oligodendrocytes (Chang et al. 2002), the presence and functional properties of axons, and the occurrence of repeated demyelination of remyelinated areas (Bramow et al. 2010). Furthermore, in rare lesions, which are affected by pronounced damage of astrocytes, remyelination may also be accomplished by Schwann cells (Itoyama et al. 1985). However, in light of recent knowledge, some of the patients described in this study may have suffered from neuromyelitis optica and not from MS. 
H. Lassmann

\section{Demyelination in the Gray Matter}

As in white matter lesions, oligodendrocyte destruction and primary demyelination is the pathological hallmark that distinguishes them from brain damage in other diseases of the CNS (Fig. 1B-D). However, the degree of inflammation, edema, microglia activation, and macrophage recruitment is much less compared with that in white matter (Peterson et al. 2001). Demyelination is associated with a variable degree of loss of axons, neurons, and glia cells, and this is accompanied by an even greater loss of synapses (Wegner et al. 2006; Dutta et al. 2011). Remyelination is more extensive in the cortex compared with the white matter (Albert et al. 2007).

\section{Types of Cortical Lesions}

Different types of cortical lesions are found in the MS brain, and their incidence is different between early relapsing and progressive MS (Kidd et al. 1999; Peterson et al. 2001; Bo et al. 2003). Type 1 lesions are present at the corticosubcortical border and affect the gray as well as the white matter. Type 2 lesions are small perivenous intracortical lesions. Type 3 lesions are located in the subpial layers of the cortex (Fig. $1 \mathrm{~B}, \mathrm{D})$. They are most abundant, in particular, in the progressive stage of the disease and are mainly located in the cortical sulci and the deep invaginations of the brain surface, such as the insular cortex or the cingulate cortex. They are associated with inflammation in the meninges and expand from the pial surface into the deeper cortical layers. A special type of cortical type 3 lesions has been classified as type 4 when it affects the entire cortex but does not pass the border between the cortex and the white matter.

\section{Diffuse Changes in Normal-Appearing White and Gray Matter}

Such alterations are most pronounced in patients with progressive MS. They consist of perivascular inflammatory infiltrates, moderate brain edema, diffuse microglia activation, diffuse axonal injury, and astrocytic gliosis (Kutzelnigg et al.
2005). Part of these changes is secondary to axonal and neuronal damage within focal lesions, which gives rise to anterograde (Wallerian) and retrograde degeneration (Dziedzic et al. 2010). Retrograde degeneration induces the accumulation of phosphorylated neurofilament within the cytoplasm of affected neurons, which is a good indicator of the severity of this process (Haider et al. 2016). However, diffuse changes in the normal-appearing white and gray matter also develops independent from focal lesions. They correlate, in part, to inflammation in the meninges covering the spinal cord or the cortex (Androdias et al. 2010; Haider et al. 2016).

\section{Differences in Pathology among Acute, Relapsing, and Progressive MS}

All typical pathological features of MS are seen in all stages of the disease (Haider et al. 2014, 2016). Thus, there is no qualitative difference in the pathology between relapsing and progressive MS, including primary progressive MS. However, the contribution of the pathological processes and alterations differs quantitatively. Focal new and active white matter lesions are most numerous in early (acute and relapsing) MS and become rare when patients have entered the progressive stage. Instead, many plaques in progressive MS fulfill the criteria of slowly expanding lesions, as described above. Cortical demyelination is already present in the earliest stages of MS (Lucchinetti et al. 2011), but its extent massively increases when patients reach the progressive stage (Kutzelnigg et al. 2005). In extreme examples of primary progressive MS, white matter lesions may be very rare and small, whereas demyelination may affect $>60 \%$ of the entire cortical area (Haider et al. 2014). Diffuse changes in the normal-appearing white matter are sparse in early MS but very pronounced in patients with progressive MS (Kutzelnigg et al. 2005).

Focal lesions in the MS brain arise around inflamed veins and venoles and, thus, areas of high venous density are more likely to be affected (Charcot 1880). In the progressive stage of the disease, however, chronic demyelinated plaques accumulate in brain areas, which have a lower 
perfusion and oxygen tension in normal individuals (the so-called watershed areas marking the borders of the territories of large cerebral arteries) (Brownell and Hughes 1962; Haider et al. 2016). This indicates that in brain regions with high-perfusion and oxygen tension, lesions formed in the early disease stages may become repaired, whereas tissue destruction, leading to permanent lesions, is more pronounced in areas of low blood perfusion (Holland et al. 2012; Haider et al. 2016). Interestingly, permanent and destructive lesions in progressive MS also accumulate in those areas, which are mainly affected by the consequences of age-related vascular disturbances such as periventricular leukoarayosis (Haider et al. 2016). These features of pathology in the progressive stage of MS are in line with the concept that oxidative injury, followed by mitochondrial injury and genetic deletions of mitochondrial DNA, are key mechanisms of tissue damage in MS, leading to "virtual hypoxia." This appears to result in energy deficiency and subsequent ionic imbalance in oligodendrocytes, axons, and neurons, which can be amplified by age-related hypoxic tissue injury (Trapp and Stys 2009; Mahad et al. 2015).

\section{INFLAMMATION}

MS has originally been defined as a chronic inflammatory disease of the CNS, which leads to demyelination and subsequent neurodegeneration (Babinski 1885). However, this view has been challenged by clinical observations that in the progressive stage, ongoing tissue damage is not associated with magnetic resonance imaging (MRI) evidence for inflammation (the detection of blood-brain barrier disturbance by Gd-leakage) and the lack of effectiveness of anti-inflammatory treatments in this stage of the disease. Furthermore, analysis of initial stages of white matter lesions showed surprisingly little inflammation in comparison to that seen in later, more advanced lesion stages (Barnett and Prineas 2004). For these reasons, it has been proposed that MS may be the result of a primary neurodegenerative process, which is modified or amplified by the inflammatory reaction (Stys et al. 2012). However, a detailed pathological analysis provides a different view, which will be discussed in detail below.

The nature of the inflammatory response in the MS brain has been in the center of interest for decades of MS research. As described above, the formation of MS lesions around veins and venoles, the association of active demyelination with inflammatory infiltrates around these vessels, as well as the diffuse spread of the inflammatory process into the affected tissue have already been noted in the earliest descriptions of this disease. Perivascular inflammatory infiltrates were found to consist mainly of lymphocytes and plasma cells, whereas active tissue damage was associated with macrophages and activated microglia. The lymphocyte population has later been defined to represent mainly $\mathrm{T}$ cells with a smaller contribution of B cells and plasma cells (Fig. 2C) (Esiri et al. 1980; Booss et al. 1983; Hayashi et al. 1988; Franciotta et al. 2008). The inflammatory process is associated with the expression of proinflammatory as well as antiinflammatory cytokines (Cannella and Raine 1995; Mycko et al. 2003) and adhesion molecules (Dore-Duffy et al. 1993; Ifergan et al. 2011; Larochelle et al. 2012, 2015) or chemokines and their receptors (Balashov et al. 1999; Holman et al. 2011), which are involved in the recruitment of different lymphocyte subsets and monocytes.

Regarding cells of the adaptive immune system, CD3-positive $\mathrm{T}$ cells are the most numerous lymphocytes in the MS brain in all lesions and at all stages of the disease. $\mathrm{CD}^{+} \mathrm{T}$ cells by far outnumber $\mathrm{CD}^{+}$cells (Fig. 2D) (Booss et al. 1983; Hayashi et al. 1988), CD20 $0^{+}$B cells, or plasma cells (Frischer et al. 2009). Clonal expansion has been mainly observed in the population of $\mathrm{CD} 8^{+}$ $\mathrm{T}$ cells and plasma cells, being much less abundant in the $\mathrm{CD} 4^{+}$population (Babbe et al. 2000; Skulina et al. 2004; Hohlfeld et al. 2016). However, there are differences in the composition of inflammatory cells in the perivascular or meningeal space and in the diffuse infiltrates in the parenchyme of the CNS. CD8 ${ }^{+} \mathrm{T}$ cells outnumber other lymphocytes in all locations, but in the perivascular and meningeal cuffs, a substantial but variable number of $\mathrm{CD} 4^{+} \mathrm{T}$ cells, $\mathrm{CD} 20^{+} \mathrm{B}$ cells, and plasma cells are present (Fig. 2A,C) 
(Babbe et al. 2000; Frischer et al. 2009). In the meninges, inflammatory cells form large aggregates, which show features of tertiary lymphatic tissue (Serafini et al. 2004; Franciotta et al. 2008; Pikor et al. 2016). This is reflected by separation of $\mathrm{T}$ cells, B cells, and plasma cells in distinct domains of the aggregates (Fig. 2A,B), and this process is associated with $\mathrm{B}$-cell proliferation and the presence of cells expressing markers of follicular dendritic cells (Serafini et al. 2004). Such inflammatory follicle-like structures in the meninges are associated with particularly severe active demyelination in the underlying cortex (Magliozzi et al. 2007). Similar, but less impressive, aggregates are also found within the large perivascular Virchow-Robin spaces of the brain. In contrast, diffuse infiltration of the brain parenchyme in lesions and the normal-appearing white matter nearly exclusively consist of $\mathrm{CD}^{+} \mathrm{T}$ cells (Fig. 2D) and, in some cases, immunoglobulin-containing plasma cells (Babbe et al. 2000; Frischer et al. 2009). Little is known so far regarding the presence of $\mathrm{T}$-cell subsets in the lesions. Some studies report high numbers of T cells expressing the transcription factor T-bet, thus suggesting the presence of $\mathrm{T}$ cells polarized into a $\gamma$-interferon-producing subset (Bsibsi et al. 2014). One study reported Il17 expression in $\mathrm{CD}^{+}$and $\mathrm{CD}^{+}$lymphocytes (Tzartos et al. 2008, 2011), but functional interpretation of these findings was complicated by the abundance of the expression of Il17 in astrocytes. Il21 was found in $\mathrm{CD}^{+}$cells, but the Il 21 receptor was broadly expressed in all lymphocyte subpopulations. In addition, Il 21 and its receptor were abundantly expressed in neurons. The functional role of the expression of these cytokines in CNS cells and how it influences lymphocyte function in the nervous system is currently unresolved. There is good agreement that FoxP3-positive regulatory cells are very sparse or even absent in MS lesions (Tzartos et al 2008; Fritzsching et al. 2011).

\section{Inflammation in Active MS Lesions}

As mentioned above, it is still controversial as to whether the inflammatory process in MS is the primary driving force of tissue damage in MS, or whether the lesions are initiated by a neurodegenerative process that is modified or amplified by the inflammatory reaction. The latter view is supported by a highly recognized study, which proposed that initial MS lesions are formed in the absence of inflammation by $\mathrm{T}$ cells and $\mathrm{B}$ cells, although these cells accumulate in advanced lesion stages after the initial destruction of oligodendrocytes by apoptosis and demyelination (Barnett and Prineas 2004). However, detailed quantitative studies following this primary observation showed that in the earliest stages of lesions there are already perivascular inflammatory infiltrates containing $\mathrm{T}$ cells and $\mathrm{B}$ cells in close proximity to the site of active tissue damage and that there is a diffuse infiltration of the initial lesions by a low number of $\mathrm{CD}^{+} \mathrm{T}$ cells, which significantly outnumber those seen in the periplaque and normal-appearing white matter of MS patients or in the white matter of controls (Marik et al. 2007; Henderson et al. 2009). In more advanced lesions in which myelin has already been destroyed and the fragments have been taken up by macrophages, a massive increase of inflammation was seen, containing not only $\mathrm{CD} 8^{+} \mathrm{T}$ cells but also $\mathrm{CD} 4^{+}$cells, $\mathrm{B}$ cells, and monocytes. These data suggest that cells of the adaptive immune system are already present in initial lesions, although in relatively small numbers, but that demyelination and tissue damage leads to a second wave of inflammation that may be caused by adhesion molecule and chemokine expression in response to tissue injury (Marik et al. 2007; Henderson et al. 2009).

\section{Inflammation in the Brain of Patients with Progressive MS}

Quantitative data of T- and B-cell infiltration in the MS brain showed the most pronounced inflammation in classical active lesions in patients with acute or relapsing MS. However, there was a lower extent of inflammation also present in inactive lesions, the normal-appearing white matter, and the meninges. In patients with progressive MS, classical active lesions are sparse or absent. In contrast, a significant number of lesions show signs of slow and chronic expansion. 
When $\mathrm{T}$ cells and $\mathrm{B}$ cells were counted in the brain of patients with progressive MS, the degree of inflammatory infiltration was very similar compared to that seen in the normal-appearing white matter, in inactive lesions, or in the meninges of patients with early (acute or relapsing) MS (Frischer et al. 2009). Furthermore, in the progressive stage of MS, lymphocyte infiltration into the tissue is 10-100 times higher than that seen in age-matched controls or in the brain of patients with stroke or neurodegenerative disease. Inflammation in progressive MS is pronounced in the meninges and the perivascular Virchow-Robin spaces, where it gives rise to large inflammatory aggregates.

Several observations suggest that in the progressive stage of MS the inflammatory response is, at least in part, trapped within the CNS behind a closed or repaired blood-brain barrier. Contrast enhancement in MRI is rare in patients with progressive MS, despite the fact that patients from a similar disease stage and with a similar disease course have substantial inflammation in the brain and spinal cord seen by pathological analysis; in many instances, perivascular and diffuse parenchymal infiltrates of lymphocytes are present in the absence of serum protein leakage (Hochmeister et al. 2006). Furthermore, the formation of inflammatory aggregates with features of tertiary lymphoid tissue is likely to be driven by the local environment or the presence of a specific antigen within the compartment of the CNS (Pikor et al. 2016).

In a subset of patients with progressive MS, the inflammatory response in the brain is comparable to that which is present in age-matched controls. This is mainly the case in patients with high-age and long-disease duration but sometimes also in younger patients with a short-disease course. Interestingly, in these patients, no active demyelination was found and the extent of acute axonal injury was similar to that seen in age-matched controls (Frischer et al. 2009). These data suggest that in MS patients in whom inflammation has ceased, demyelination and active tissue injury declines to the levels associated with brain aging. Thus, such patients may reflect a stage of "burnt-out" MS. However, in such patients with severe MS-related pathol- ogy, which has passed the threshold of functional compensation, even minor age-related neurodegeneration may increase clinical disability, thus giving rise to further clinical disease progression.

All of the above-described findings support the view that inflammation drives demyelination and neurodegeneration in MS. Whether there are, however, differences in the nature of the inflammatory response between early and late MS, which additionally may explain the difference in the effectiveness of anti-inflammatory treatments between patients in these two different disease stages, remains unresolved.

\section{HOW IS INFLAMMATION CONNECTED TO DEMYELINATION AND NEURODEGENERATION IN THE MS BRAIN?}

As mentioned above, the key feature of MS pathology is the selective primary nature of the demyelinating process. Based on knowledge from experimental models, there are many different immunological mechanisms that may be involved in this process, and the question arises, which of these mechanisms are relevant for MS (Lucchinetti et al. 2000; Lassmann et al. 2012). Because subpial cortical lesions in the MS brain are the most specific pathological feature of the disease, their detailed analysis in comparison to cortical damage in other human diseases may provide information regarding disease mechanisms.

\section{Demyelination in MS is Not a Nonspecific (Bystander) Consequence of the Inflammatory Process}

Subpial cortical lesions are not seen in any other inflammatory brain disease that affects the cortex (Moll et al. 2008). This is the case even in chronic inflammatory diseases such as tuberculous or luetic meningoencephalitis diseases, which have meningeal and cortical inflammatory infiltrates with a composition that is very similar to that seen in MS. Subpial cortical demyelination is also absent in Rasmussen's encephalitis or paraneoplastic encephalitis, diseases with a dominant (or even exclusive) $\mathrm{CD}^{+} \mathrm{T}$-cell-me- 
diated pathogenesis. Furthermore, no demyelination is detected in patients with meningeal or diffuse infiltration by neoplastic B cells in cases with B-cell lymphoma (Fischer et al. 2013). These observations clearly show that primary demyelination in MS is not a nonspecific (bystander) consequence of brain inflammation.

\section{Demyelination and Neurodegeneration May Be Triggered by a Soluble Factor Produced by Lymphocytes}

Active subpial cortical lesions in MS show a characteristic architecture. T lymphocytes, B lymphocytes, and plasma cells are located in the meninges and their presence is clearly associated with activity of demyelination and neurodegeneration in the underlying cortex (Figs. 2A, $\mathrm{B}$ and $3 \mathrm{~B}, \mathrm{D})$. However, active demyelination within the cortex in most cases occurs in the absence of diffuse T-cell, B-cell, and plasmacell infiltration in the cortical tissue, but is associated with activated microglia at sites distant from the cells of the adaptive immune response. The best explanation for such a pattern of tissue damage is that soluble factors are produced in the meningeal inflammatory infiltrates, which diffuse into the cortex and induce demyelination either directly or indirectly through microglia activation (Magliozzi et al. 2007). Such a pathogenic cascade of events could also resolve the controversy regarding the relation between inflammation and neurodegeneration at other sites of the MS brain. The low-tissue infiltration of actively demyelinating lesions by lymphocytes, as seen not only in the cortex but also in initial white matter lesions, makes it unlikely that demyelination and axonal damage is induced by a direct contact between the target cells and lymphocytes. The inflammatory cells are, however, present in the perivascular space within and around active lesions and these inflammatory cells may trigger tissue damage through the action of a soluble factor.

A similar pattern of cortical demyelination, as seen in MS patients, is well reflected in primates and rats with experimental autoimmune encephalomyelitis when the disease is induced by the combination of an encephalitogenic
T-cells response and the presence of specific demyelinating antibodies (Pomeroy et al. 2005; Storch et al. 2006). In this case, encephalitogenic $\mathrm{T}$ cells induce inflammation, blood-brain barrier damage, activation of macrophages or microglia, and the accumulation of $B$ cells and plasma cells in the meninges and perivascular spaces. Demyelination, however, is triggered by the binding of specific demyelinating antibodies and accomplished through complement activation or antibody-dependent cellular cytotoxicity. These observations stimulated an intense international effort to search for demyelinating or cytotoxic autoantibodies in the serum and cerebrospinal fluid (CSF) of MS patients. In an in vitro study, antibodies binding to oligodendrocytes or myelin have been observed in 30\%-50\% of the MS sera tested (Lily et al. 2004; Elliott et al. 2012). So far, however, the identification of an MS-specific target for such antibodies has failed. Myelin oligodendrocyte glycoprotein would be an obvious candidate, but antibodies against this protein have only been identified in patients (mainly children) with acute or relapsing disseminated encephalomyelitis, and the presence of such antibodies may indicate that the patients do not have MS but a newly defined myelin oligodendrocyte glycoprotein antibody-associated autoimmune syndrome (Kim et al. 2015). Analysis of antibodies derived from clonally expanded plasma cells from the patient's CSF showed some binding to neurons, astrocytes, and oligodendrocytes and induced demyelination in vitro, but, so far, the specific target antigens have not been identified (Blauth et al. 2015). Furthermore, demyelinating or cytotoxic activity of serum or CSF of MS patients may also be caused by as-yet-unidentified factors, which are produced by B cells but are still present when immunoglobulins are removed from the samples (Grundke Iqbal and Bornstein 1980; Lisak et al. 2012). A recent study identified ceramide as a potential cytotoxic factor in the MS CSF, which may induce neuronal injury through oxidative damage in vitro (Vidaure et al. 2014). Although this is a very interesting candidate, it cannot explain how such a lipid factor will be able to diffuse from the meningeal inflammatory infiltrates to the site of active demyelination in 
the cortex. Overall, these data indicate that there are one or several soluble demyelinating and/or cytotoxic factors produced in the inflammatory process in MS, but their biochemical nature will have to be defined in future studies.

Demyelination and Neurodegeneration Is Finally Accomplished by Microglia Activation, Oxidative Injury, and "Virtual Hypoxia"

As described so far, inflammatory demyelinating lesions in MS are specific for the disease and not seen in other inflammatory or neurodegenerative diseases affecting the cerebral cortex. This made it possible to directly compare gene expression in active cortical MS lesions with that seen in control populations, including tuberculous meningoencephalitis (as an inflammatory control), Alzheimer's disease (as a control for neurodegeneration), and normal controls without neurological disease or brain lesions (Fischer et al. 2013). A limited number of genes, which showed differential expression in active MS lesions, were identified. The differentially expressed genes coded for proteins involved in inflammation, active tissue injury, and demyelination or neurodegeneration. Regarding active tissue injury, the molecules that appeared in this analysis were mainly related to oxidative burst in microglia, mitochondrial damage, and cell degeneration. The gene expression changes were then validated by pathological analysis and immunocytochemistry. These investigations showed that degenerating neurons, myelin, and oligodendrocytes identified by the fragmentation of their processes and apoptosis show profound lipid oxidation (Fischer et al. 2013). This process is associated with mitochondrial damage reflected by the presence of respiratory-deficient cells and the accumulation of mitochondrial gene deletions (Dutta et al. 2006; Mahad et al. 2008; Campbell et al. 2011). Profound oxidative injury is also seen in active white matter lesions in early MS (Fischer et al. 2012). Mitochondrial injury appears to be in the center of the pathogenic cascade, giving rise to a state of "virtual hypoxia" and to the amplification of oxidative injury through electron leakage (Mahad et al. 2015). A consequence of "virtual hypoxia" is energy deficiency, which results in ionic dysbalance in affected cells and cell degeneration through $\mathrm{Ca}^{2+}$-dependent pathways (Stys et al. 2012). As discussed above, such a pathogenetic cascade may explain the distribution of lesions in the MS brain, and it will also be amplified in the progressive stage of the disease by brain aging and mechanisms related to the accumulation of lesion burden in the CNS (Haider et al. 2016). Key questions, however, remain unresolved. It is currently not clear why such a profound oxidative injury specifically occurs in MS lesions in comparison to other inflammatory diseases of the CNS. It also must be determined in the future whether this exaggerated oxidative injury is related to an MS-specific inflammatory process or, in part, is influenced by mechanisms that regulate the susceptibility of the target tissue in the MS brain and spinal cord.

\section{CONCLUSIONS}

Experimental studies performed during the last decade have identified a large number of immunological and neurobiological mechanisms that may be involved in the regulation of inflammation in MS and in the induction of tissue damage in the CNS. Which of these mechanisms are relevant for the disease process in MS patients can, in part, be identified in pathological studies of the lesions in the CNS of the patients. On the basis of such a pathological analysis, a number of mechanistic insights are suggested, which appear to be relevant for the understanding of the disease process in MS:

1. The pathological data provide strong support for the concept that inflammation drives demyelination and tissue injury in all stages of the disease. However, demyelination and neurodegeneration is not a nonspecific (bystander) consequence of the inflammatory process, but is MS-specific.

2. The low number of lymphocytes at the sites of active demyelination and neurodegeneration makes it unlikely that tissue injury is triggered by a direct interaction of these cells with the target tissue, but that it is mediated by soluble factors produced by lymphocytes 
H. Lassmann

that induce damage either directly or indirectly through microglia activation.

3. Although demyelinating and cytotoxic activity is present in the sera and CSF of the patients, the nature of this soluble factor is currently undefined.

4. A dominant mechanism finally leading to demyelination and neurodegeneration is a cascade of oxidative injury, mitochondrial damage, "virtual hypoxia," and its downstream molecular consequences. This mechanism becomes particularly prominent in patients with progressive MS, because it is amplified by factors related to brain aging and the accumulation of lesion burden in the CNS. What primarily causes this exaggerated oxidative and mitochondrial injury in MS patients is currently unresolved.

\section{REFERENCES}

Albert M, Antel J, Brück W, Stadelmann C. 2007. Extensive cortical remyelination in patients with chronic multiple sclerosis. Brain Pathol 17: 129-138.

Androdias G, Reynolds R, Chanal M, Ritleng C, Confavreux C, Nataf S. 2010. Meningeal T cells associate with diffuse axonal loss in multiple sclerosis spinal cords. Ann Neurol 68: 465-476.

Babbe H, Roers A, Waisman A, Lassmann H, Goebels N, Hohlfeld R, Friese M, Schröder R, Deckert M, Schmidt S, et al. 2000. Clonal expansion of $\mathrm{CD}^{+} \mathrm{T}$ cells dominate the $\mathrm{T}$ cell infiltrate in active multiple sclerosis lesions as shown by micromanipulation and single cell polymerase chain reaction. J Exp Med 192: 393-404.

Babinski J. 1885. Recherches sur ĺanatomie pathologique de la sclerose en plaque et etude comparative des diverses varietes de la scleroses de la moelle [Research on the anatomic pathology of multiple sclerosis and a comparative study on different forms of scaring of the spinal cord] Arch Physiol (Paris) 5-6: 186-207.

Balashov KE, Rottman JB, Weiner HL, Hancock WW. 1999. $\mathrm{CCR}^{+}$and $\mathrm{CXCR}^{+}{ }^{+} \mathrm{T}$ cells are increased in multiple sclerosis and their ligands MIP- $1 \alpha$ and IP-10 are expressed in demyelinating brain lesions. Proc Natl Acad Sci 96: 6873-6878.

Barnett MH, Prineas JW. 2004. Relapsing and remitting multiple sclerosis: Pathology of the newly forming lesion. Ann Neurol 55: 458-468.

Bauer J, Gold R, Adams O, Lassmann H. 2015. Progressive multifocal leukoencephalopathy and immune reconstitution inflammatory syndrome (IRIS). Acta Neuropathol 130: 751-764.

Blauth K, Soltys J, Matschulat A, Reiter CR, Ritchie A, Baird NL, Bennett JL, Owens GP. 2015. Antibodies produced by clonally expanded plasma cells in multiple sclerosis cere- brospinal fluid cause demyelination of spinal cord explants. Acta Neuropathol 130: 765-781.

Bo L, Vedeler CA, Nyland HI, Trapp BD, Mork SJ. 2003. Subpial demyelination in the cerebral cortex of multiple sclerosis patients. J Neuropath Exp Neurol 62: 723-732.

Booss J, Esiri MM, Tourtellotte WW, Mason DY. 1983. Immunohistological analysis of T lymphocyte subsets in the central nervous system in chronic progressive multiple sclerosis. J Neurol Sci 62: 219-232.

Bramow S, Frischer JM, Lassmann H, Koch-Henriksen N, Lucchinetti CF, Sørensen PS, Laursen H. 2010. Demyelination versus remyelination in progressive multiple sclerosis. Brain 133: 2983-2998.

Brownell B, Hughes JT. 1962. The distribution of plaques in the cerebrum in multiple scleosis. J Neurol Neurosurg Psychiatr 25: 315-320.

Brück W, Porada P, Poser S, Riechmann P, Hanefeld F, Kretschmar HA, Lassmann H. 1995. Monocyte/macrophage differentiation in early multiple sclerosis lesions. Ann Neurol 38: 788-796.

Bsibsi M, Peferoen LA, Holtman IR, Nacken PJ, Gerritsen WH, Witte ME, van Horssen J, Eggen BJ, van der Valk P, Amor S, et al. 2014. Demyelination during multiple sclerosis is associated with combined activation of microglia/ macrophages by IFN- $\gamma$ and $\alpha$ B-crystallin. Acta Neuropathol 128: 215-229.

Campbell GR, Ziabreva I, Reeve AK, Krishnan KJ, Reynolds R, Howell O, Lassmann H, Turnbull DM, Mahad DJ. 2011. Mitochondrial DNA deletions and neurodegeneration in multiple sclerosis. Ann Neurol 69: 481-492.

Cannella B, Raine CS. 1995. The adhesion molecule and cytokine profile of multiple sclerosis lesions. Ann Neurol 37: 424-435.

Chang A, Tourtellotte WW, Rudick R, Trapp BD. 2002. Premyelinating oligodendrocytes in chronic lesions of multiple sclerosis. N Engl J Med 346: 165-173.

Charcot JM. 1880. Lecons sur les maladies du systeme nerveux faites a la Salpetriere [Lectures about the diseases of the nervous system done at the Salpetriere], 4th ed., Vol. 1A. Delahaye, Paris.

Cifelli A, Arridge M, Jezzard P, Esiri MM, Palace J, Matthews PM. 2002. Thalamic neurodegeneration in multiple sclerosis. Ann Neurol 52: 650-653.

Dawson JW. 1916. The histology of disseminated sclerosis. Trans R Soc 50: 517-540.

Dore-Duffy P, Washington R, Dragovic L. 1993. Expression of cell activation antigens in microvessels from patients with multiple sclerosis. Adv Exp Med Biol 331: 243-248.

Dutta R, McDonough J, Yin X, Peterson J, Chang A, Torres T, Gudz T, Macklin WB, Lewis DA, Fox RJ, et al. 2006. Mitochondrial dysfunction as a cause of axonal degeneration in multiple sclerosis patients. Ann Neurol 59: 478-489.

Dutta R, Chang A, Doud MK, Kidd GJ, Ribuado MV, Young EA, Fox RJ, Staugaitis SM, Trapp BD. 2011. Demyelination causes synaptic alterations in hippocampi from multiple sclerosis patients. Ann Neurol 69: 445-454.

Dziedzic T, Metz I, Dallenga T, König FB, Müller S, Stadelmann C, Brück W. 2010. Wallerian degeneration: A major 
component of early axonal pathology in multiple sclerosis. Brain Pathol 20: 976-985.

Elliott C, Lindner M, Arthur A, Brennan K, Jarius S, Hussey J, Chan A, Stroet A, Olsson T, Willison H, et al. 2012 Functional identification of pathogenic autoantibody responses in patients with multiple sclerosis. Brain 135: 1819-1833.

Esiri MM. 1980. Multiple sclerosis: A quantitative and qualitative study of immunoglobulin-containing cells in the central nervous system. Neuropathol Appl Neurobiol 6: 921.

Ferguson B, Matyszak MK, Esiri MM, Perry VH. 1997. Axonal damage in acute multiple sclerosis lesions. Brain 120: 393-399.

Fischer MT, Sharma R, Lim J, Haider L, Frischer J, Drexhage J, Mahad D, Bradl M, van Horssen J, Lassmann H. 2012 NADPH oxidase expression in active multiple sclerosis lesions in relation to oxidative tissue damage and mitochondrial injury brain 135: 886-899.

Fischer MT, Wimmer I, Höftberger R, Gerlach S, Haider L, Zrzavy T, Hametner S, Mahad D, Binder CJ, Krumbholz $\mathrm{M}$, et al. 2013. Disease-specific molecular events in cortical multiple sclerosis lesions. Brain 136: 1799-1815.

Fog T. 1950. Topographic distribution of plaques in the spinal cord in multiple sclerosis. Arch Neurol Psychiatr 63: 382-414.

Franciotta D, Salvetti M, Lolli B, Aloisi F. 2008. B cells and multiple sclerosis. Lancet Neurol 7: 852-858.

Frischer JM, Bramow S, Dal Bianco A, Lucchinetti CF, Rauschka H, Schmidbauer M, Laursen H, Sorensen PS, Lassmann H. 2009. The relation between inflammation and neurodegeneration in multiple sclerosis brains. Brain 132: $1175-1189$.

Frischer J, Weigand S, Guo Y, Kale N, Parisi J, Pirko I, Mandrekar J, Bramow S, Metz I, Brück W, et al. 2015. Clinical and pathological insights into the dynamic nature of the white matter multiple sclerosis plaque. Ann Neurol 78: 710-721.

Fritzsching B, Haas J, König F, Kunz P, Fritzsching E, Pöschl J, Krammer PH, Brück W, Suri-Payer E, Wildemann B. 2011. Intracerebral human regulatory T cells: Analysis of $\mathrm{CD}^{+} \mathrm{CD}^{+} 5^{+} \mathrm{FOXP}^{+} \mathrm{T}$ cells in brain lesions and cerebrospinal fluid of multiple sclerosis patients. PLoS ONE 6: e17988.

Grundke Iqbal I, Bornstein MB. 1980. Multiple sclerosis: Serum $\gamma$ globulin and demyelination in culture. Neurology 30: $749-754$

Haider L, Simeonidou C, Steinberger G, Hametner S, Grigoriadis N, Deretzi G, Kovacs G, Kutzelnigg A, Lassmann H, Frischer J. 2014. Multiple sclerosis deep grey matter: The relation between demyelination, neurodegeneration, inflammation and iron. J Neurol Neurosurg Psychiatry 85: 1386-1395.

Haider L, Zrzavy T, Hametner S, Höftberger R, Bagnato F, Grabner G, Trattnig S, Pfeifenbring S, Brück W, Lassmann H. 2016. The topograpy of demyelination and neurodegeneration in the multiple sclerosis brain. Brain 139: 807-815.

Hayashi T, Morimoto C, Burks JS, Kerr C, Hauser SL. 1988. Dual-label immunocytochemistry of the active multiple sclerosis lesion: Major histocompatibility complex and activation antigens. Ann Neurol 24: 523-531.
Henderson APD, Barnett MH, Parratt JDE, Prineas JW. 2009. Multiple sclerosis: Distribution of inflammatory cells in newly forming lesions. Ann Neurol 66: 739-753.

Hochmeister S, Grundtner R, Bauer J, Engelhardt B, Lyck R, Gordon G, Korosec T, Kutzelnigg A, Berger JJ, Bradl M, et al. 2006. Dysferlin is a new marker for leaky brain blood vessels in multiple sclerosis. J Neuropathol Exp Neurol 65: 855-865.

Hohlfeld R, Dornmair K, Meinl E, Wekerle H. 2016. The search for target antigens of multiple sclerosis. Part 2 : $\mathrm{CD}^{+} \mathrm{T}$ cells, $\mathrm{B}$ cells, and antibodies in the focus of reverse-translational research. Lancet Neurol 15: 317-331.

Holland CM, Charil A, Csapo I, Liptak Z, Ichise M, Khoury SJ, Bakshi R, Weiner HL, Guttmann CR. 2012. The relationship between normal cerebral perfusion patterns and white matter lesion distribution in 1,249 patients with multiple sclerosis. J Neuroimaging 22: 129-136.

Holman DW, Klein RS, Ransohoff RM. 2011. The blood brain barrier, chemokines and multiple sclerosis. Biochim Biophys Acta 1812: 220-230.

Ifergan I, Kebir H, Terouz S, Alvarez JL, Lecuyer MA, Gendron S, Bourbonniere A, Moumdjian R, Fontana A, Haggani A, et al. 2011. Role of ninjurin-1 in the migration of myeloid cells to central nervous system inflammatory lesions. Ann Neurol 79: 751-763.

Itoyama Y, Ohnishi A, Tateishi J, Kuroiwa Y, Webster HD. 1985. Spinal cord multiple sclerosis lesions in Japanese patients: Schwann cell remyelination occurs in areas that lack glial fibrillary acidic protein (GFAP). Acta Neuropathol 65: 217-223.

Kidd T, Barkhof F, McConnell R, Algra PR, Allen IV, Revesz T. 1999. Cortical lesions in multiple sclerosis. Brain 122: $17-26$.

Kim SM, Woodhall MR, Kim JS, Kim SJ, Park KS, Vincent A, Lee KW, Waters P. 2015. Antibodies to MOG in adults with inflammatory demyelinating disease. Neurol Neuroimmunol Neuroinflamm 2: e163.

Kornek B, Lassmann H. 1999. Axonal pathology in multiple sclerosis: A historical note. Brain Pathol 9: 651-656.

Kornek B, Storch M, Weissert R, Wallstroem E, Stefferl A, Olsson T, Linington C, Schmidbauer M, Lassmann H. 2000. Multiple sclerosis and chronic autoimmune encephalomyelitis: A comparative quantitative study of axonal injury in active, inactive and remyelinated lesions. Amer J Pathol 157: 267-276.

Kutzelnigg A, Lassmann H. 2014. Pathology of multiple sclerosis and related inflammatory demyelinating diseases. Handb Clin Neurol 122: 15-58.

Kutzelnigg A, Lucchinetti CF, Stadelmann C, Brück W, Rauschka H, Bergmann M, Schmidbauer M, Parisi J, Lassmann H. 2005. Cortical demyelination and diffuse white matter injury in multiple sclerosis. Brain 128: 2705-2712.

Kutzelnigg A, Faber-Rod JC, Bauer J, Lucchinetti CF, Sorensen PS, Laursen H, Stadelmann C, Brück W, Rauschka H, Schmidbauer M, et al. 2007. Widespread demyelination in the cerebellar cortex in multiple sclerosis. Brain Pathol 17: 38-44.

Larochelle C, Cayrol R, Kebir H, Alvarez JI, Lecuver MA, Ifergan I, Viel E, Bourbonniere L, Beauseigle D, Terouz S, et al. 2012. Melanoma cell adhesion molecule identifies encephalitogenic $\mathrm{T}$ lymphocytes and promotes their re- 
H. Lassmann

cruitment to the central nervous system. Brain 135: 29062924.

Larochelle C, Lecuyer MA, Alvarez JI, Saint-Laurent O, Ghannam S, Kebir H, Flanagan K, Yednock T, Duquette P, Arbour N, et al. 2015. Melanoma cell adhesion molecule-positive CD8 $\mathrm{T}$ lymphocytes mediate central nervous system inflammation. Ann Neurol 78: 39-53.

Lassmann H, Bruck W, Lucchinetti CF. 2007. The immunopathology of multiple sclerosis: An overview. Brain Pathol 17: $210-218$

Lassmann H, van Horssen J, Mahad D. 2012. Progressive multiple sclerosis: Pathology and pathogenesis. Nat Rev Neurol 8: 647-656.

Lily O, Palace J, Vincent A. 2004. Serum autoantibodies to cell surface determinants in multiple sclerosis: A flow cytometric study. Brain 127: 269-279.

Lisak RP, Benjamins JA, Nedelkoska L, Barger JL, Ragheb S, Fan B, Ouamara N, Johnson TA, Rajasekharan S, Bar-Or A. 2012. Secretry products of multiple sclerosis B-cells are cytotoxic to oligodendrocytes in vitro. J Neuroimmunol 246: 85-95.

Lucchinetti C, Brück W, Parisi J, Scheithauer B, Rodriguez M, Lassmann H. 2000. Heterogeneity of multiple sclerosis lesions: Implications for the pathogenesis of demyelination. Ann Neurol 47: 707-717.

Lucchinetti CF, Popescu BFG, Bunyan RF, Moll NM, Roemer SF, Lassmann H, Brück W, Parisi JE, Scheithauer BW, Giannini C, et al. 2011. Inflammatory cortical demyelination in early multiple sclerosis. N Engl J Med 365: 2188-2197.

Magliozzi R, Howell O, Vora A, Serafini B, Nicholas R, Puopoplo M, Reynolds R, Aloisi F. 2007. Meningeal B-cell follicles in secondary progressive multiple scleroses associate with early onset of disease and severe cortical pathology. Brain 130: 1089-1104.

Mahad D, Ziabreva I, Lassmann H, Turnbull D. 2008. Mitochondrial defects in acute multiple sclerosis lesions. Brain 131: 1722-1735

Mahad DH, Trapp BD, Lassmann H. 2015. Pathological mechanisms in progressive multiple sclerosis. Lancet Neurol 14: 183-193.

Marik C, Felts P, Bauer J, Lassmann H, Smith KJ. 2007. Lesion genesis in a subset of patients with multiple sclerosis: A role for innate immunity? Brain 130: 2800-2815.

Misu T, Höftberger R, Fujihara K, Wimmer I, Takai Y, Nishiyama S, Nakashima I, Konno H, Bradl M, Garzuly F, et al. 2013. Presence of six different lesion types suggests diverse mechanisms of tissue injury in neuromyelitis optica. Acta Neuropathol 125: 815-827.

Moll NM, Rietsch AM, Ransohoff AJ, Cossoy MB, Huang D, Eichler FS, Trapp BD, Ransohoff RH. 2008. Cortical demyelination in PML and MS: Similarities and differences. Neurology 70: 336-343.

Mycko MP, Papoian R, Boschert U, Raine CS, Selmaj KW. 2003. cDNA microarray analysis in multiple sclerosis lesions: Detection of genes associated with disease activity. Brain 126: 1048-1057.

Patrikios P, Stadelmann C, Kutzelnigg A, Rauschka H, Schmidbauer M, Laursen H, Soelberg Sorensen P, Brück
W, Lucchinetti C, Lassmann H. 2006. Remyelination is extensive in a subset of multiple sclerosis patients. Brain 129: 3165-3172.

Peterson JW, Bo L, Mork S, Chang A, Trapp BD. 2001. Transsected neurites, apoptotic neurons and reduced inflammation in cortical multiple sclerosis lesions. Ann Neurol 50: 389-400.

Pikor NB, Prat A, Bar Or A, Gommerman JL. 2016. Meningeal tertiary lymphoid tissues and multiple sclerosis: A gathering place for diverse types of immune cells during CNS autoimmunity. Front Immunol 6: e657.

Pomeroy IM, Matthews PM, Frank JA, Jordan EK, Esiri MM. 2005. Demyelinated neocortical lesions in marmoset autoimmune encephalomyelitis mimic those in multiple sclerosis. Brain 128: 2713-2721.

Prineas JW. 1985. The neuropathology of multiple sclerosis. In Handbook of clinical neurology (ed. Koetsier JC), Vol. 47, pp. 337-395. Elsevier, New York.

Prineas JW, Barnard RO, Kwon EE, Sharer LR, Cho ES. 1993. Multiple sclerosis: Remyelination of nascent lesions. Ann Neurol 33: 137-151.

Prineas JW, Kwon EE, Cho ES, Sharer LR, Barnett MH, Oleszak EL, Hoffman B, Morgan BP. 2001. Immunopathology of secondary-progressive multiple sclerosis. Ann Neurol 50: 646-657.

Serafini B, Rosicarelli B, Magliozzi R, Stigliano E, Aloisi F. 2004. Detection of ectopic B-cell follicles with germinal centers in the meninges of patients with secondary progressive multiple sclerosis. Brain Pathol 14: 164-174.

Skulina C, Schmidt S, Dornmair K, Babbe H, Roers A, Rajewsky K, Wekerle H, Hohlfeld R, Goebels N. 2004. Multiple sclerosis: Brain infiltrating $\mathrm{CD}^{+} \mathrm{T}$ cells persist as clonal expansions in the cerebrospinal fluid and blood. Proc Natl Acad Sci 101: 2428-2433.

Storch MK, Bauer J, Linington C, Olsson T, Weissert R, Lassmann H. 2006. Cortical demyelination can be modeled in specific rat models of autoimmune encephalomyelitis and is major histocompatability complex (MHC) haplotype-related. J Neuropathol Exp Neurol 65: 11371142.

Stys P, Zamponi GW, Van Minnen J, Geurts J. 2012. Will the real multiple sclerosis please stand up? Nat Rev Neurosci 13: 507-514.

Trapp B, Stys P. 2009. Virtual hypoxia and chronic necrosis of demyelinated axons in multiple sclerosis. Lancet Neurol 8: 280-291.

Trapp BD, Peterson J, Ransohoff RM, Rudick R, Mork S, Bo L. 1998. Axonal transection in the lesions of multiple sclerosis. N Engl J Med 338: 278-285.

Tzartos JS, Friese MA, Craner MJ, Palace J, Newcombe J, Esiri MM, Fugger L. 2008. Interleukin 17 production in central nervous system infiltrating $\mathrm{T}$ cells and glial cells is associated with active disease in multiple sclerosis. Am J Pathol 172: 146-156.

Tzartos JS, Craner MJ, Friese MA, Jakobsen KB, Newcombe J, Esiri MM, Fugger L. 2011. Il-21 and Il-21 eeceptor expression in lymphocytes and neurons in multiple sclerosis. Amer J Pathol 178: 794-802.

Vercellino M, Masera S, Lorenzatti M, Condello C, Merola A, Mattioda A, Tribolo A, Capello E, Mancardi GL, Mutani 
R, et al. 2009. Demyelination, inflammation, and neurodegeneration in multiple sclerosis deep grey matter. $J$ Neuropath Exp Neurol 68: 489-502.

Vidaure OG, Haines JD, Katz Sand I, Adula KP, Huynh JL, McGraw CA, Zhang F, Varghese M, Sotirchos E, Bhargava VV, et al. 2014. Cerebrospinal fluid ceramides from patients with multiple sclerosis impair neuronal bioenergetics. Brain 137: 2271-2286.
Vogel DY, Vereyken EJ, Glim JE, Heijnen PD, Moeton M, van der Valk P, Amor S, Teunissen CE, van Horssen J, Dijkstra CD, et al. 2013. Macrophages in inflammatory multiple sclerosis lesions have an intermediate activation status. J Neuroinflammation 10: e35.

Wegner C, Esiri MM, Chance SA, Palace J, Matthews PM. 2006. Neocortical neuronal, synaptic, and glial loss in multiple sclerosis. Neurology 67: 960-967. 


\section{$\&_{\mathrm{CSH}}^{\infty} \&$ Cold Spring Harbor

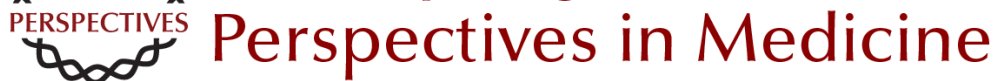

\section{Multiple Sclerosis Pathology}

Hans Lassmann

Cold Spring Harb Perspect Med 2018; doi: 10.1101/cshperspect.a028936 originally published online January 22, 2018

\section{Subject Collection Multiple Sclerosis}

Multiple Sclerosis Pathology

Hans Lassmann

Regulatory T Cells: From Discovery to

Autoimmunity

Alexandra Kitz, Emily Singer and David Hafler

The Multiple Roles of B Cells in Multiple Sclerosis and Their Implications in Multiple Sclerosis

Therapies

Rui Li and Amit Bar-Or

Autologous Hematopoietic Stem Cell

Transplantation in the Treatment of Multiple

Sclerosis

Carolina A. Rush, Harold L. Atkins and Mark S.

Freedman

B-Cell Therapies in Multiple Sclerosis

Joseph J. Sabatino, Jr., Scott S. Zamvil and Stephen L. Hauser

Oral Therapies for Multiple Sclerosis Simon Faissner and Ralf Gold

Interferon $\beta$ for Multiple Sclerosis

Dejan Jakimovski, Channa Kolb, Murali

Ramanathan, et al.

Alemtuzumab as Treatment for Multiple Sclerosis Serafeim Katsavos and Alasdair Coles
Natalizumab: Perspectives from the Bench to

Bedside

Afsaneh Shirani and Olaf Stüve

Daclizumab Therapy for Multiple Sclerosis Bibiana Bielekova

Lifestyle and Environmental Factors in Multiple

Sclerosis

Lars Alfredsson and Tomas Olsson

Biomarkers in Multiple Sclerosis

Anu Paul, Manuel Comabella and Roopali Gandhi

The Evolving Mechanisms of Action of Glatiramer

Acetate

Thomas Prod'homme and Scott S. Zamvil

Regulation of Astrocyte Functions in Multiple Sclerosis

Michael A. Wheeler and Francisco J. Quintana

Experimental Autoimmune Encephalomyelitis

(EAE) as Animal Models of Multiple Sclerosis (MS)

Simon Glatigny and Estelle Bettelli

Neurodegeneration in Progressive Multiple

Sclerosis

Graham Campbell and Don Mahad

For additional articles in this collection, see http://perspectivesinmedicine.cshlp.org/cgi/collection/ 